\title{
Commentary
}

\section{How to Keep COVID-19 at Bay: A Taiwanese Perspective}

\author{
Chih-Cheng Lai ${ }^{1}$, Muh-Yong Yen², Ping-Ing Lee ${ }^{3}$, Po-Ren Hsueh ${ }^{4 *}$ \\ ${ }^{1}$ Department of Internal Medicine, Kaohsiung Veterans General Hospital, Tainan Branch, Tainan, Taiwan \\ ${ }^{2}$ Division of Infectious Diseases, Taipei City Hospital, School of Medicine, National Yang-Ming University, Taipei, Taiwan \\ ${ }^{3}$ Department of Pediatrics, National Taiwan University Children's Hospital and National Taiwan University College of Medicine, Taipei, Taiwan \\ ${ }^{4}$ Departments of Laboratory Medicine and Internal Medicine, National Taiwan University Hospital, National Taiwan University College of Medicine, \\ Taipei, Taiwan
}

\author{
ARTICLE INFO \\ Article History \\ Received 06 August 2020 \\ Accepted 17 October 2020 \\ Keywords \\ COVID-19 \\ Taiwan \\ Border control \\ big data \\ Real-name Mask System
}

(C) 2020 The Authors. Published by Atlantis Press International B.V. This is an open access article distributed under the CC BY-NC 4.0 license (http://creativecommons.org/licenses/by-nc/4.0/).

\section{COVID-19 PANDEMIC}

Coronavirus Disease (COVID-19), caused by the Severe Acute Respiratory Syndrome Coronavirus 2 (SARS-CoV-2), was first reported in Wuhan, China, in December 2019. COVID-19 spread rapidly across China in the first 2 months of 2020 [1,2]. Strategies and tools have been developed and implemented for COVID-19 mitigation in many countries [3,4], with no exception for Taiwan, which is located approximately 100 miles off the coast of southeastern China. Many people frequently travel between Taiwan and China. Therefore, it was predicted that Taiwan will have the second highest number of confirmed COVID-19 cases. However, this disastrous outcome was avoided due to the prompt and significant actions of Taiwanese authorities, including the early deployment of resources [5,6]. In addition, previous experiences from the SARS and H1N1 outbreaks in 2003 and 2009, respectively, have helped the Taiwanese government to effectively improve the strategies for novel pandemic preparedness and to establish a public health response mechanism that will enable rapid action against future crises [7]. To date, SARS-CoV-2 has infected $>18,000,000$ people and caused $>690,000$ deaths globally $[1,2]$. As of August 23, 2020, 168,216 people in Taiwan had been tested for SARS-CoV-2, of whom 487 were confirmed positive, with an incidence rate of 20.5 per 1,000,000 people [2]. Of the 487 patients with COVID-19, $55(11.3 \%)$ acquired the infection via community transmission and seven died, representing a case fatality rate of only $1.4 \%$ [2].

“Corresponding author.Email: hsporen@ntu.edu.tw

\section{EARLY RESPONSE (JANUARY 2020)}

Taiwanese authorities responded in several ways, including increasing air and sea border control from China, identification of positive cases, quarantine of suspected cases, and institution of holiday extensions for students and travel restrictions (including those for medical staff). In addition, Taiwanese authorities prohibited the exportation of surgical masks and began manufacturing them in order to avoid shortages, due to concerns that these would become a crucial tool against COVID-19 transmission. On January 20, the Central Epidemic Command Center (CECC) was established to coordinate inter-ministerial responses and to prevent the highly transmissible SARS-CoV-2 from devastating the island country. During this period, press conferences by the CECC were conducted at least once a day to present timely information on the extent of the spread of COVID-19 in Taiwan and announce updated policies and measures.

On January 25, the CECC decided to integrate travel history data from the National Immigration Agency using PharmaCloud, a system designed to provide clinicians with access to travel history. Patient travel history helped physicians determine whether patients with respiratory symptoms should be tested for SARS-CoV-2. The database integration also enabled the back-tracing of patient records and their travel history for retrospective testing. On April 1, 2020, the CECC announced social distancing measures, in addition to the use of face masks, to reduce the risk of community transmission of SARS-CoV-2. Currently, the CECC recommends that people should maintain a physical distance from others of at least $1.5 \mathrm{~m}$ indoors and $1 \mathrm{~m}$ outdoors. The long holiday period from 
April 2 to 5 included the Tomb Sweeping Festival and Children's Day. Several popular parks, temples, and markets were crowded. During this time, the CECC disseminated information via mobile emergency alerts to advise people to wear masks and practice social distancing. Moreover, since April 4, 2020, wearing face masks has been mandated for all citizens accessing public transport, including the high-speed rail system, city metro systems, buses, and taxis (since April 5). A maximum fine of NT \$15,000 (US \$496) was levied for noncompliance.

Although border control was initially established only for China, this strategy has been expanded to all countries. All passengers arriving in Taiwan from other countries who presented with fever or any respiratory symptoms or signs were immediately required to undergo a test for SARS-CoV-2 and to file their information at the airport, including whether they had experienced any associated disease symptoms. All data were uploaded to the centralized database of the Centers for Disease Control in Taiwan (Taiwan CDC) for further tracking. Before they could leave the airport, passengers had to ensure that they were registered in the CDC online database and could successfully receive text messages from the CDC. This enabled the government to confirm that everyone had completed their 14-day quarantine at home or in a hotel. The passengers were then transported home via a special government-provided quarantine taxi service, as they were not allowed to use any public transportation. In addition, to evacuate Taiwanese citizens from the Hubei province in China (the epicenter of COVID-19), authorities arranged cross-strait charters from Wuhan to Taiwan on February 3 (246 passengers) and March 10 (361 passengers). Any passenger who displayed symptoms was immediately sent to a hospital for full diagnosis and treatment. Those with no symptoms were isolated for 14 days at three undisclosed quarantine locations to prevent them from encountering local residents.

\section{COMMUNITY MITIGATION}

From January to April 2020, the reporting criteria continuously evolved in accordance with the increased understanding of the epidemiological characteristics and clinical manifestations of COVID-19. This enabled designated hospitals to maintain high-quality medical care through the optimal admission of patients without missing any potential COVID-19 cases [8]. The presence of fever and associated respiratory symptoms such as pneumonia, tachypnea, or respiratory difficulties was included in the first set of clinical criteria but was deleted in the second set. Acute respiratory infection with or without fever, community-acquired pneumonia, loss of taste or smell, and diarrhea of unknown etiology were added to the latest version of the clinical criteria. The epidemiological criteria were frequently revised in accordance with changes in the epidemic regions over time. All COVID-19 diagnoses were confirmed by the detection of SARS-CoV-2 using Real-time Reverse Transcription Polymerase Chain Reaction (qRT-PCR).

\section{HEALTH-CARE SYSTEM MITIGATION}

Each hospital was required to make an inventory of personal protective equipment, including surgical masks, gowns, gloves, hand disinfectants, and other equipment. In the early stages of the outbreak, most entrances to hospital buildings were closed as soon as possible. Outdoor quarantine stations, where the body temperatures and travel histories [obtained by checking the National Health Insurance (NHI) identification card] of all visitors were assessed, were set up in front of hospital entrances. In addition, all hospital visitors were required to wear masks and use an alcohol-based disinfectant spray for hand hygiene when they entered and exited the hospital. Currently, only staff members, patients, and caregivers are allowed to enter hospitals. Healthcare workers in hospitals are required to check their body temperature daily and report whether they have any respiratory symptoms [9]. To prevent unintentional nosocomial spread, several hospitals set up isolation rooms (without negative pressure) as quarantine wards to admit patients suggested as having SARS-CoV-2 infection while awaiting qRT-PCR results $[10,11]$. The use of these enhanced traffic control bundling measures ensured that transmission via droplets, fomites, and contact was prevented within and between hospitals and in the wider communities [11,12].

The collection of clinical specimens for SARS-CoV-2 testing was most commonly performed in emergency departments; it was time-consuming and required substantial personal protective equipment. Therefore, several hospitals in Taiwan designed a multifunctional sample collection station for COVID-19 testing in front of emergency departments or within hospitals. This strategy helped to save time during sample collection and reduced the use of personal protection equipment [13]. In addition, one hospital introduced a strategy of including double triage and a telemedicine protocol in the emergency department to help reduce the exposure time and risk of contracting SARS-CoV-2 for frontline healthcare workers when managing patients suspected of having COVID-19 [14].

In Taiwan, one nurse at a nursing home tested positive for SARSCoV-2 on March 22, 2020, and the authorities immediately intervened. All residents were moved to a nearby hospital and two quarantine locations. The Long-term Care Facility (LTCF) was then closed and disinfected. The authorities also identified additional people who had been in contact with the nurse before her diagnosis and closely monitored their clinical conditions. One week later, the nurse tested negative for SARS-CoV-2 in a repeat test, and all the contacts also tested negative [15].

\section{UTILIZATION OF BIG DATA}

After the initial prohibition of the exportation and the subsequent increase in the manufacturing of surgical masks, Taiwan promptly acquired the capability to produce masks domestically along with a cloud computing system for mask rationing. On March 10, 2020, the CECC announced that preorders of masks can be made through a new system (called the Real-name Mask System 2.0) for mask purchases. To ensure that all residents complied with the rules when purchasing masks, masks were made available for purchase at designated pharmacies, drugstores, and medical centers. These locations have the capability to digitally scan NHI identification cards, which allow the government to record purchase histories. Taiwan's mask rationing program initially resulted in long queues at pharmacies. This problem was not solved by the release of a list of pharmacies and the stock of 
masks available at each location by the Ministry of Health and Welfare. Information technology engineers used NHI data on pharmacy locations and mask stocks to create maps with information on real-time mask availability to help address this issue. Finally, Taiwan conducted trials for online mask ordering or a "name-based rationing system." Residents with NHI cards were able to preorder masks online and collect them at convenience stores. Owing to the immediate popularity of this system, web traffic was initially overwhelming despite the reliability testing. After the first trial, the system was adjusted to enable people to collect their masks within a shorter time. The trial system was reviewed weekly for modifications. Adults and children using this system were permitted to purchase nine and ten masks, respectively, within 14 days since April 9. Beginning from April 19, due to an increasing number of people purchasing masks through the eMask system, face masks were no longer distributed to pharmacies contracted by the NHI Administration and local public health centers on Sundays to allow personnel to have time off. On April 22, 2020, Taiwan began to roll out the Realname Mask System 3.0, which allowed the public to visit a convenience store and buy masks within seconds. Mask availability is one of the most important measures in preventing the spread of COVID-19 in Taiwan [16]. A study on Mass General Brigham, the largest health-care system in Massachusetts, also supports universal masking as part of a multipronged infection reduction strategy in healthcare settings [17]. However, data regarding the prevalence of mask use in Taiwan are lacking. Further studies using photo-epidemiology to estimate the face covering use are warranted $[18,19]$.

In addition, the use of big data analytics with digital contact tracing, mobile geo-positioning, automated alert messaging for selfrestriction, and follow-up of outcomes associated with COVID-19 using NHI claims data has curtailed the resources required for the conventional epidemiological contact tracing of the 627,386 persons who were in contact with the Diamond Princess Cruise Ship passengers who disembarked in Taiwan [20].

\section{EPIDEMIC NEW LIFE MOVEMENT DURING RECOVERY}

The absence of locally transmitted cases since April 12, 2020, has allowed health authorities to begin the gradual lifting of the epidemic prevention measures to allow the public to engage in some normal activities. On April 12, the regular season of the Chinese Professional Baseball League (CPBL) was launched without spectators, which was the only such activity scheduled anywhere worldwide during the COVID-19 pandemic. On May 1, the CECC eased restrictions on visits to LTCFs to allow name-based visits. Since May 8, 2020, the Epidemic New Life Movement has been initiated to instruct people on how to safely return to their normal lives in Taiwan after a long period without domestic COVID-19 cases. All citizens could feel safe to shop and dine at any store and restaurant if the following four epidemic control requirements were met: (1) social distancing $(1 \mathrm{~m}$ outdoors and $1.5 \mathrm{~m}$ indoors with alternate seat arrangements or partitions between seats); (2) personal hygiene and protective equipment (mask wearing, body temperature checks, and handwashing/cleaning agents at the entrance or in venues); (3) use of the Real-name Mask System to distribute masks (registration of customer names, customer traffic control, and environmental cleaning and disinfection); and (4) qualified fire and public building safety. At this time, each CPBL regular season game can be attended by a maximum of 1000 spectators. On May 22, a new bilingual chatbot in Google Assistant was developed to serve as another channel for the public to receive up-to-date information such as introductory information on COVID-19, methods of transmission, symptoms, epidemic status within other countries/regions, and information on the stock of face masks in each pharmacy. On May 23, the CECC announced that members of the public could undergo COVID-19 testing at their own expense at 18 designated hospitals in emergency situations and for work and international study requirements.

In the United States, school closures were temporally found to be associated with decreased COVID-19 incidence and mortality [21]. Although seven cases have been confirmed in six universities in Taiwan, only one university was temporarily closed; however, it was quickly reopened 14 days later. In fact, reopening colleges and universities during the COVID-19 pandemic has been a great challenge in all countries. In Taiwan, the Ministry of Education developed general guidelines for each school to maintain the health of students and staff since the early stages of the pandemic. Recommendations included establishing a task force, school-based risk screening, self-management of health and quarantine, and some infection control and prevention policies. Classes would be suspended if one student or staff member tested positive for SARSCoV-2, and the school would be closed for 14 days if two or more tested positive for SARS-CoV-2. Under the implementation of these recommendations, schools in Taiwan have been functioning well since their reopening [22].

\section{COLLATERAL BENEFIT OF INFECTION CONTROL}

The implementation of the above-mentioned interventions not only helped Taiwan ensure a relatively safe status early in the COVID-19 pandemic, but also provided the additional benefit of infection control. In addition to the low number of cases of SARS-CoV-2 infection in Taiwan, the incidence of other common infections such as seasonal influenza, outpatient pneumonia, enterovirus, scarlet fever, and tuberculosis was lower than that in previous years $[23,24]$. This can be partly attributed to the effectiveness of the wide implementation of public health precautions against COVID-19, such as mask wearing and hand hygiene, which helped prevent droplet and contact transmissions [23].

\section{CONCLUSION}

Overall, Taiwan's aggressive efforts and preemptive deployment of response actions prevented the rapid spread of SARS-CoV-2 infection in the country (Table 1) [25]. Taiwan did not institute a lockdown, which has been the case in many other countries and cities worldwide. Nevertheless, vigilance is necessary, as COVID-19 continues to pose a major challenge for the country. 
Table 1 Major measures of coronavirus disease 2019 (COVID-19) prevention and control in Taiwan

\begin{tabular}{|c|c|}
\hline Date & Measures \\
\hline December 31, 2019 & $\begin{array}{l}\text { Implemented relevant prevention strategies, including surveillance, laboratory diagnosis, border control, control of community } \\
\text { transmission, medical system response and preparedness, stockpile and allocation of Personal Protective Equipment and other } \\
\text { medical supplies, health education, and disinformation management }\end{array}$ \\
\hline January 15,2020 & Classified COVID-19 as a category 5 communicable disease \\
\hline January 20, 2020 & $\begin{array}{l}\text { Established the Central Epidemic Command Center to coordinate inter-ministerial responses, mobilize resources, and conduct } \\
\text { daily press briefing }\end{array}$ \\
\hline January 23, 2020 & On board quarantine inspection of travelers from Wuhan, China \\
\hline January 24,2020 & Banned the exportation of medical masks \\
\hline January 25, 2020 & $\begin{array}{l}\text { Established PharmaCloud to integrate travel history data from the National Immigration Agency to provide clinicians with access } \\
\text { to travel history }\end{array}$ \\
\hline January 26, 2020 & Urged healthcare facilities to reinforce the reporting of suspected cases and the public to abide by the prevention measures implemented \\
\hline February 1, 2020 & Monitored the situation of the COVID-19 outbreak and urged travelers to reinforce personal prevention measures \\
\hline February 2, 2020 & Decided that all primary and secondary schools should postpone their first day of spring semester \\
\hline February 6, 2020 & Launched the name-based rationing system for the purchasing of masks \\
\hline February 10, 2020 & $\begin{array}{l}\text { Required 14-day home quarantine for travelers transiting through China, Hong Kong, and Macau and granted entry into Taiwan; } \\
\text { implemented restrictions on direct flights to and from China, Hong Kong, and Macau and suspected flights from certain airports }\end{array}$ \\
\hline March 1, 2020 & Central and local governments implemented the plan for providing services for home-quarantined/isolated individuals \\
\hline March 5, 2020 & Issued Guidelines for Large-Scale Public Gatherings \\
\hline March 10, 2020 & Implemented Real-name Mask System for preordering of masks \\
\hline March 19, 2020 & Prohibited travelers from foreign nationals \\
\hline March 25, 2020 & Recommended suspending indoor gatherings of over 100 people and outdoor gatherings of over 500 people to prevent cluster infections \\
\hline April 1, 2020 & Announced social-distancing measures and established related guidelines and recommendations \\
\hline April 5, 2020 & Mandated face mask weaning for all citizens accessing public transporters \\
\hline April 9, 2020 & Adults were eligible for nine masks and ten child-sized face masks were allowed for children every 14 days \\
\hline April 19, 2020 & $\begin{array}{l}\text { Face masks would not be distributed to pharmacies contracted by the National Health Insurance Administration and local public } \\
\text { health centers every Sunday to allow the personnel to have time off to rest. }\end{array}$ \\
\hline April 22, 2020 & Real-name Mask System 3.0 allowed the public to visit a convenience store and buy masks within seconds \\
\hline May 1,2020 & Eased restrictions on visits to long-term care facilities to allow name-based visiting \\
\hline May 8, 2020 & Implemented the EPIDEMIC NEW LIFE MOVEMENT while gradually easing the restrictions \\
\hline May 22,2020 & Launched the bilingual chatbot on Google Assistant launched \\
\hline May 30, 2020 & $\begin{array}{l}\text { Taiwan Food and Drug Administration approved the importation of the anti-viral drug remdesivir to ensure the treatment of } \\
\text { patients with severe COVID-19 }\end{array}$ \\
\hline June 1,2020 & Masks not requisitioned by the government \\
\hline June 19,2020 & Eased visitor restrictions at healthcare facilities \\
\hline June 22,2020 & Allowed entry for short-term business travelers and applied shortened home-quarantine periods \\
\hline June 25, 2020 & Allowed transit passengers at Taiwan Taoyuan International Airport with thorough route and monitoring measures \\
\hline August 1,2020 & Allowed foreign nationals to receive medical treatment in Taiwan \\
\hline
\end{tabular}

\section{CONFLICTS OF INTEREST}

The authors declare they have no conflicts of interest.

\section{AUTHORS' CONTRIBUTION}

The authors contributed equally to the article.

\section{REFERENCES}

[1] World Health Organization (WHO). Available from: https:// www.who.int/emergencies/diseases/novel-coronavirus-2019 (accessed on August 3, 2020).

[2] Centers for Diseases Control and Prevention of Taiwan (Taiwan CDC). Available from: https://www.cdc.gov.tw/en/Disease/ SubIndex/ (accessed on August 4, 2020).

[3] Ebrahim SH, Zhuo J, Gozzer E, Ahmed QA, Imtiaz R, Ahmed Y, et al. All Hands on Deck: a synchronized whole-of-world approach for COVID-19 mitigation. Int J Infect Dis 2020;98;208-15.
[4] Ebrahim SH, Ahmed QA, Gozzer E, Schlagenhauf P, Memish ZA. Covid-19 and community mitigation strategies in a pandemic. BMJ 2020;368;m1066.

[5] Wang CJ, Ng CY, Brook RH. Response to COVID-19 in Taiwan: big data analytics, new technology, and proactive testing. JAMA 2020;323;1341-2.

[6] Lai CC, Wang CY, Wang YH, Hsueh SC, Ko WC, Hsueh PR. Global epidemiology of coronavirus disease 2019 (COVID-19): disease incidence, daily cumulative index, mortality, and their association with country healthcare resources and economic status. Int J Antimicrob Agents 2020;55;105946.

[7] Yen MY, Chiu AWH, Schwartz J, King CC, Lin YE, Chang SC, et al. From SARS in 2003 to H1N1 in 2009: lessons learned from Taiwan in preparation for the next pandemic. J Hosp Infect 2014;87;185-93.

[8] Huang YC, Lee PI, Hsueh PR. Evolving reporting criteria of COVID-19 in Taiwan during the epidemic. J Microbiol Immunol Infect 2020;53;413-18.

[9] Yang CJ, Chen TC, Chen YH. The preventive strategies of community hospital in the battle of fighting pandemic COVID-19 in Taiwan. J Microbiol Immunol Infect 2020;53;381-3. 
[10] Lai CC, Liu YH, Wang CY, Wang YH, Hsueh SC, Yen MY, et al. Asymptomatic carrier state, acute respiratory disease, and pneumonia due to severe acute respiratory syndrome coronavirus 2 (SARS-CoV-2): facts and myths. J Microbiol Immunol Infect 2020;53;404-12.

[11] Yen MY, Schwartz J, Chen SY, King CC, Yang GY, Hsueh PR. Interrupting COVID-19 transmission by implementing enhanced traffic control bundling: implications for global prevention and control efforts. J Microbiol Immunol Infect 2020;53;377-80.

[12] McMichael TM, Currie DW, ClarkS, Pogosjans S, Kay M, Schwartz NG, et al. Epidemiology of Covid-19 in a long-term care facility in King County, Washington. N Engl J Med 2020;382;2005-11.

[13] Lin PT, Ni TY, Chen TY, Su CP, Sun HF, Chen MK, et al. Reducing the consumption of personal protective equipment by setting up a multifunctional sampling station in the emergency department to screen for COVID-19 infection in Taiwan. Environ Health Prev Med 2020;25;34.

[14] Lin CH, Tseng WP, Wu JL, Tay J, Cheng MT, Ong HN, et al. A double triage and telemedicine protocol to optimize infection control in an emergency department in Taiwan during the COVID-19 pandemic: retrospective feasibility study. J Med Internet Res 2020;22; 20586.

[15] Lai CC, Wang JH, Ko WC, Yen MY, Lu MC, Lee CM, et al. COVID-19 in long-term care facilities: an upcoming threat that cannot be ignored. J Microbiol Immunol Infect 2020;53;444-6.

[16] Su VYF, Yen YF, Yang KY, Su WJ, Chou KT, Chen YM, et al. Masks and medical care: two keys to Taiwan's success in preventing COVID-19 spread. Travel Med Infect Dis 2020;101780.
[17] Wang X, Ferro EG, Zhou G, Hashimoto D, Bhatt DL. Association between universal masking in a health care system and SARS-CoV-2 positivity among health care workers. JAMA 2020;324;703-4.

[18] Elachola H, Ebrahim SH, Gozzer E. COVID-19: facemask use prevalence in international airports in Asia, Europe and the Americas, March 2020. Travel Med Infect Dis 2020;35;101637.

[19] Elachola H, Gozzer E, Mujeeb Rahman NM, Ditekemena J, Pando-Robles V, Pa K, et al. Photo-epidemiology to estimate face covering use in select areas in Asia versus the Americas and Africa during the COVID-19 pandemic. J Travel Med 2020;taaa121.

[20] Chen CM, Jyan HW, Chien SC, Jen HH, Hsu CY, Lee PC, et al. Containing COVID-19 among 627,386 persons in contact with the Diamond Princess Cruise Ship passengers who disembarked in Taiwan: big data analytics. J Med Internet Res 2020;22;e19540.

[21] Auger KA, Shah SS, Richardson T, Hartley D, Hall M, Warniment A, et al. Association between statewide school closure and COVID-19 incidence and mortality in the US. JAMA 2020;324;859-70.

[22] Cheng SY, Jason Wang C, Shen ACT, Chang SC. How to safely reopen colleges and universities during COVID-19: experiences from Taiwan. Ann Intern Med 2020;173;638-41.

[23] Lee HH, Lin SH. Effects of COVID-19 prevention measures on other common infections, Taiwan. Emerg Infect Dis 2020;26;2509-11.

[24] Lai CC, Yu WL. The COVID-19 pandemic and tuberculosis in Taiwan. J Infect 2020;81;e159-e61.

[25] Centers for Diseases Control and Prevention of Taiwan (Taiwan CDC). Available from: https://www.cdc.gov.tw/En/Category/ Page/0vq8rsAob_9HCi5GQ5jH1Q (accessed August 4, 2020). 